
2 Research Square
Preprints are preliminary reports that have not undergone peer review.
They should not be considered conclusive, used to inform clinical practice, or referenced by the media as validated information.

\title{
The study of the impact factors of behaviors of nursing intern students: PRECEDE-based structural equation modeling analysis
}

\author{
Li Zhang \\ Chongqing Medical University \\ Yetao Luo \\ Chongqing Medical University Affiliated Children's Hospital \\ Yanhan Chen ( $\square$ Yanhan@hospital.cqmu.edu.cn ) \\ Chongqing Medical University
}

\section{Research}

Keywords: tobacco dependence treatment, smoking cessation, interventions, nursing intern student $₫$ As,PRECEDE, Structural equation model

Posted Date: August 26th, 2020

DOI: https://doi.org/10.21203/rs.3.rs-56287/v1

License: (c) (i) This work is licensed under a Creative Commons Attribution 4.0 International License. Read Full License 


\section{Abstract}

Background

Tobacco hazard is known as one of the most critical public health problems. Nurses could and should help patients to quit smoking. However, the lack of tobacco cessation education of nurses at medical school leads to the absence of behaviors helping smokers to quit. The analysis of the factors that influencing the nursing interns to help smokers to quit provide evidence for nursing school to administer tobacco cessation education to facilitate more behaviors of smoking cessation in future nurses.

Object

To explore the interaction and the effect coefficient among the influencing factors of the 5 As behaviors of nursing interns in helping smokers to quit provide and to provide evidences for the tobacco cessation education.

Method: Based on the PRECEDE theory, a questionnaire was developed with consideration of predisposing factor, enabling factor and reinforcing factor. Random Cluster Sampling was used to conduct a survey in 13 teaching hospitals selected from 29 in Chongqing to assess the 5 As behaviors of all nursing interns. A structural equation model was established to test the path and effect coefficient of their 5 As behaviors.

Results

The survey investigated 1358 nurses, and the model fitted well with the data. The tobacco cessation education, one of the enabling factors, imposed max effect on the $5 A$ s of nursing interns directly $\varangle \beta=0.542 \rrbracket p<0.001 \rrbracket$ and indirectly $\varangle \beta=0.38 \rrbracket p<0.001 \rrbracket$ through self-efficacy. The reinforcing factors ( smoking cessation environment) imposed direct effect $\varangle \beta=0.305 \rrbracket p<0.001$ \and indirect effect on the 5 As of nursing interns through attitude changes. Predisposing factors including self-efficacy influenced the 5 As directly, while attitude $\varangle \beta=0.001 \rrbracket p<0.05 \rrbracket$ and knowledge $\varangle \beta=0.008 \rrbracket p<0.05 \rrbracket$ of tobacco cessation implied indirect influence on the 5As through self-efficacy change.

Conclusion

Tobacco cessation education was the major factor that influenced the nursing interns' behaviors of helping patients to quit smoking. Enhanced responsibility of smoking cessation education and skills training of clinical teachers can prompt them to actively help patients to quit smoking, actively instruct students the knowledge and skills of smoking quit to increase students' behavior of helping smokers to quit.

\section{Background}

Tobacco hazard is known the most critical public health problems. A total of 8 millions died from tobacco use annually ${ }^{[1]}$. China is the largest producer and consumer of tobacco products, accounting for $40 \%$ of the global cigarettes ${ }^{[2]}$. China has 316 million current smokers and over $1 \mathrm{million}$ died from diseases because of tobacco use every year ${ }^{[3]}$.

The Framework Convention on Tobacco Control of WHO stresses the important function of health professionals in smoking cessation and prevention, and puts request on them to perform brief consultation and offer simple advises for smokers to quit smoking ${ }^{[4]}$. Nurses are the largest group of health professionals. They offer medical and health services in hospitals, schools, communities and other places. They are extraordinary important for health promotion and playing significant roles in public health across the world ${ }^{[5]}$, and are also critical power to influence the social smoking pattern. Therefore, nurses play pivotal role in smoking cessation ${ }^{[6]}$

Nursing students are potential nurses and are supposed to learn the updated knowledge of tobacco cessation. They should assume good self-control in smoking meanwhile help others quit smoking. A few factors that influence the involvement of students in tobacco cessation include the knowledge of and attitudes towards smoking cessation, self-smokers or not ${ }^{[7]}$. Smoker students presented negative belief in smoking cessation, and they lack identity with professional roles in helping smokers quit ${ }^{[8]}$ and hold incorrect conceptions of tobacco dependence treatment with a consideration of ineffective short consultation and treatment for the enhancement of smoking cessation rate ${ }^{[9]}$. Those factors exert negative effect on the implementation of tobacco cessation, so they provide much lower rate of smoking cessation consultation than non-smoker students ${ }^{[10]}$. The absence of relative education induces inappropriate knowledge of tobacco and smoking. Global Healthcare Professional Students Survey (GHPSS) found that merely $22.6 \%$ respondents had ever received formal training about tobacco cessation ${ }^{[11]}$. Sarna ${ }^{[12]}$ proposed to conduct tobacco use control education in nursing students. Afterwards, lots of schools launched relative education among students including nursing and medical students ${ }^{[13-15]}$. Then some studies began to explore the effect of characteristics of courses on the conception and knowledge of students in helping smokers to quit ${ }^{[16]}$.

Except the above factors, none is known to influence nursing students to help clients to quit smoking, and it is not clear how those factors interact with each other. Behavior presence is characterized with complexity and variety. Many theories have studied the causes of the occurrence of behaviors. The mode of PRECEDE-PROCEED, proposed by Greens, et al. ${ }^{[17]}$, is a commonly used way of health promotion, which is framed theoretically with PRECEDE囚Predisposing, Reinforcing, and Enabling Causes in Educational Diagnosis and Evaluation) and PROCEED (Policy, Regulatory, and Organizational Constructs in Educational and Environmental Development). PRECEDE summarizes the factors that influence the desired behaviors as predisposing factors, enabling factors and reinforcing factors when education evaluation is performed. PROCEED provides support for policy, regulation, and organizational construction when education intervention is implemented, evaluating the effect of the intervention on the quality of life and health of the targeted population. Compared to traditional health education, the Green mode is multidisciplinary based and well specific, universally applied in the field of health education ${ }^{[18-19]}$.

Page 2/11 
Therefore, based on the theory of PRECEDE, this study is to evaluate the influencing factors of the 5As in smoking cessation from predisposing factor, reinforcing factor and enabling factor. It is to be tested and verified by structural equation model and to analyze the degree of influence and interrelation of the factors.

\section{Methods}

\section{1 theories and indexes}

PRECEDEXPredisposing, Reinforcing, and Enabling Causes in Educational Diagnosis and Evaluation) is the evaluation phase of Green mode, also known as ecological mode of health promotion. Green mode stresses the conduction of ample evaluation of factors which influence behaviors: predisposing factor, enabling factor and reinforcing factor when developing health education plan. 『predisposing factor: the internal basis for behavior occurrence, including knowledge, belief, attitude, self-efficacy, etc. of the individual; 凶enabling factor: the premise of the realization of behavior motivation and willingness, that is, the necessary skills, resources and social conditions for the realization or formation of behavior changes; 『reinforcing factor: the factor that provide continuous incentives for long-term maintenance or repetition of behaviors after occurrence. The predisposing factor is the internal motivation, and the enabling factor and reinforcing factor are the external conditions.

(1) predisposing factor

The theory believes "predisposing factor" would influence behaviors. This study, considering its characteristics, defined the core variables: Predisposing factors are students' knowledge, attitudes, self-efficacy et, al. related to smoking cessation.

Among the questions about the knowledge of smoking cessation: 6 about tobacco epidemic, 10 about tobacco and disease, 5 about the harm of secondsmoking on families and 9 about the regulations of smoking cessation.

Attitudes towards the participation in smoking cessation: $₫$ Medical professionals should routinely implement the 5 As to help smokers to quit; $\varangle$ It is the responsibility of medical professional to help smokers to quit. Responses ranked from strongly disagree to strongly agree, scored on a scale of 1-5.

Self-efficacy: It is the proficiency of 5As in helping patients to quit smoking. Responses were from fully unskilled to very skilled, scored on a scale of 1-4.

(2) Enabling factor

The available tobacco cessation instruction and resources include the tobacco cessation education and guidance to students. Resources cover the familiarity with China Clinical Smoking Cessation Guidelines, tobacco cessation websites, smoking control drugs and consulting-phone number. Responses were from completely unknown to well known, scored on a scale of 1-5. The duration of tobacco cessation education for nursing students at school was: 0 minute, 30 minutes, 30-60 minutes, 1-2 hours, 2-3 hours, 3-4 hours, $4-5$ hours or more than 5 hours. The number of 5 As instructions from clinical tutors was also considered as one of the resources.

(3) Reinforcing factors

They were the factors that reinforce or interfere behaviors, such as the observations of 5As performed by clinical nurses in internship. Responses were scored 1 when never seen 5As performed by tutors in clinic, 2 when twice seen, 3 when 4-9 times seen, 4 when $10-25$ times seen and 5 when over 25 times seen. When nursing students implement smoking cessation interventions, if they felt their behaviors were consistent with the setting, as well as the practice and expectation of tutors, they would reinforce and maintain those interventions.

(4) Result variables

The 5As interventions performed by students on patients in the period of internship: asking patients the status of smoking, advising smokers to quit, assessing the tobacco dependence and willingness to quit, assisting patients to quit and arranging following up services for those who were trying to quit. The number of patients helped by students with 5 As was taken as result variable: $1=$ none patients, $2=1-3$ patients, $3=4-9$ patients, $4=10-25$ patients and $5=>25$ patients.

2.2 Pathway hypothesis that influences the 5 As of nursing students to help patients to quit smoking

Green Mode told whether implementing health behaviors or not would be influenced by predisposing factors (knowledge, attitude and self-efficacy) and enabling factors (objective conditions and resources limitation), as well as reinforcing factors ( self-feeling and evaluation from others). Consequently, the pathway hypothesis was designed:

$\mathrm{H} 1$ : Knowledge of tobacco cessation directly influences 5 As performance

$\mathrm{H} 2$ : Attitudes towards tobacco cessation directly influences $5 \mathrm{As}$ performance

H3: Self-efficacy of tobacco cessation directly influences 5 As performance

H4: Education of tobacco cessation directly influences 5 As performance

H5: Resources of tobacco cessation directly influences 5As performance

Page 3/11 
H6: Environment of tobacco cessation directly influences 5 As performance

H7: Resources of tobacco cessation indirectly influences 5 As performance through self-efficacy

H8: Education of tobacco cessation promotes self-efficacy and indirectly influences 5 As performance

H9: Education of tobacco cessation enhances knowledge and indirectly influences 5 As performance

H10: Education of tobacco cessation indirectly influences 5As performance through attitudes

H11: Environment of tobacco cessation indirectly influences 5 As performance through attitudes

H12: Environment of tobacco cessation indirectly influences 5 As performance through self-efficacy

H13: Attitudes towards tobacco cessation change the acquisition of relevant knowledge and indirectly influences 5 As performance

H14: Self-efficacy of tobacco cessation indirectly influences 5 As performance through attitudes

H15: Knowledge of tobacco cessation facilitate self-efficacy and indirectly influences 5 As performance

See pathway in figure 1

2.3 Research objects and data collection

The design and method of this cross-sectional study in Chongqing has been previously reported ${ }^{[20]}$. To get to know the 5 As behaviors and influencing factors of nursing students in helping smokers to quit in clinic work, a web-based survey was conducted among nursing students in 13 teaching hospitals in Chongqing in January 2019. The study was approved by the ethics committee of the First Affiliated Hospital of Chongqing Medical University (2019-157). The participants were nursing students who were taking clinical practicum before graduation. A total of 1522 students participated in the study, with a response rate of $62.4 \%$ (1522 / 2400), excluding questionnaires fulfilled less than 180 seconds and addressed with non Chongqing areas. The effective questionnaires were 1358 with an effective rate of $89.2 \%$.

\subsection{Statistics and analysis}

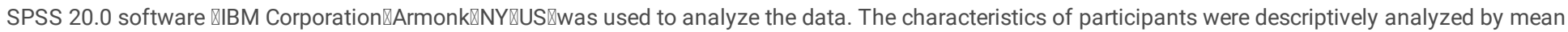
and standard deviation or constituent ratio. A structural equation model was developed by the software of Amos 24 through path analysis. Firstly, confirmatory factor analysis was used to test the measurement variables whose effectiveness was evaluated by the measurement results of SEM. Factor load indicated how much they contributed to latent variables, and aggregation validity evaluated the internal consistency of the questionnaire through composite reliability (CR) and average variance extracted (AVE). This study described the differential validity through the comparison of the square value of the correlation coefficient between AVE and latent variables. When AVE was higher than the square value of the correlation coefficient among latent variables, the differential validity between latent variables was better. The latent variables included smoking cessation knowledge, attitude, self-efficacy, education, resources, environment and 5 As behaviors. Then, a structural equation model was used to test the relationship among target variables. This model made an assessment by generalized least square (GLS) instead of maximum likelihood (ML), because the data went beyond the hypothesis of multivariate normality and the sample size was quite large. The theoretical mode was tested and revised until it was theoretically and statistically acceptable. Generally, the ratio of chi square to degree of freedom was used to assess the model fit, and the relative chi square should be less than 2.0. But it was sensitive to the sample size and a large size might induce a significant chi square. Thus, other variable measures had also been adopted, including Root Mean Square Error of Approximation

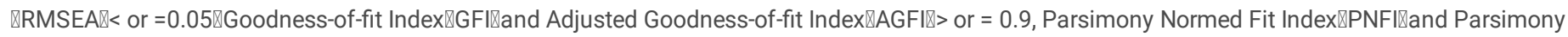

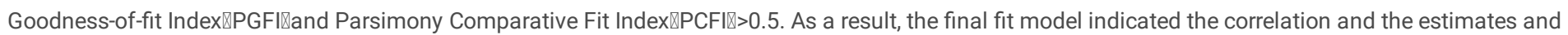
levels of regression parameters.

\section{Results}

3.1 Demographic characteristics of participants and $5 \mathrm{As}$

Demographic characteristics: Students aged 16-32, average $20.15 \pm 1.920,101$ males (7.4\%) and 1257 females (92.6\%),36 (2.7\%) current smokers, 19 (18.8\%)men and 17 (1.4\%)women. The characteristics of the participants had been reported in relevant literature ${ }^{[20]}$. Among the 1358 students, 1243 (91.5\%) ever asked about the status of smoking, 1148 (84.5\%) advised smokers to quit, 1115 (82.1\%) assessed the willingness of patients to quit smoking, 1080 (79.5\%) assisted smokers to quit, and 974 (71.7\%) arranged follow- up service about smoking quit. Details of Ask, Advice, Assess, Assist, Arrange seen in table 1.

Table1 The frequency of 5 As of students in assisting patients $\square \mathrm{N}=1358 \square$ 


\begin{tabular}{|c|c|c|c|c|c|c|c|c|c|c|}
\hline \multirow[t]{2}{*}{ The numbers of patient helped } & \multicolumn{2}{|l|}{ Ask } & \multicolumn{2}{|c|}{ Advice } & \multicolumn{2}{|c|}{ Assess } & \multicolumn{2}{|c|}{ Assist } & \multicolumn{2}{|c|}{ Arrange } \\
\hline & $\mathrm{N}$ & $\%$ & $\mathrm{~N}$ & $\%$ & $\mathrm{~N}$ & $\%$ & $\mathrm{~N}$ & $\%$ & $\mathrm{~N}$ & $\%$ \\
\hline 0 & 115 & 8.5 & 210 & 15.5 & 243 & 17.9 & 278 & 20.5 & 384 & 28.3 \\
\hline $1-3$ & 378 & 27.8 & 430 & 31.7 & 435 & 32.0 & 436 & 32.1 & 397 & 29.2 \\
\hline $4-9$ & 344 & 25.3 & 361 & 26.6 & 348 & 25.6 & 343 & 25.3 & 313 & 23.0 \\
\hline $10-25$ & 236 & 17.4 & 201 & 14.8 & 189 & 13.9 & 174 & 12.8 & 147 & 10.8 \\
\hline$>25$ & 285 & 21.0 & 156 & 11.5 & 143 & 10.5 & 127 & 9.4 & 117 & 8.6 \\
\hline
\end{tabular}

3.2 Measurement model

3.2.1 Confirmatory factor analysis

The load factor of this study was from 0.436 to 0.952 . All CRS were higher than the threshold value 0.6 , indicating good reliability [21]. Except the dimension of knowledge, the mean variance of each structure was more than 0.5 , suggesting that the factors were fully integrated ${ }^{[21-22]}$. Table 3 displayed the statistical outcomes of confirmatory factor analysis.

Table 3 Statistical outcomes of confirmatory factor analysis 


\begin{tabular}{|c|c|c|c|c|c|}
\hline Variables & Latent variables & Measure variables & Load factor & $\mathrm{CR}$ & AVE \\
\hline & \multirow[t]{3}{*}{ Knowledge } & Harm of second-hand smoking on families & 0.692 & 0.632 & 0.372 \\
\hline & & Tobacco-related disease knowledge & 0.669 & & \\
\hline & & Smoking-ban in public places & 0.436 & & \\
\hline & \multirow[t]{2}{*}{ Attitude } & B1 & 0.864 & \multirow[t]{2}{*}{0.729} & \multirow[t]{2}{*}{0.579} \\
\hline & & B2 & 0.642 & & \\
\hline & \multirow[t]{5}{*}{ Self-efficacy } & $\mathrm{C} 1$ & 0.582 & \multirow[t]{5}{*}{0.893} & \multirow[t]{5}{*}{0.630} \\
\hline & & $\mathrm{C} 2$ & 0.747 & & \\
\hline & & $\mathrm{C} 3$ & 0.909 & & \\
\hline & & $\mathrm{C} 4$ & 0.789 & & \\
\hline & & $\mathrm{C} 5$ & 0.897 & & \\
\hline \multirow[t]{10}{*}{ Enabling factors } & \multirow[t]{4}{*}{ Resources } & F10 & 0.893 & \multirow[t]{4}{*}{0.883} & \multirow[t]{4}{*}{0.666} \\
\hline & & $\mathrm{F} 11$ & 0.942 & & \\
\hline & & $\mathrm{F} 12$ & 0.858 & & \\
\hline & & F13 & 0.491 & & \\
\hline & \multirow{6}{*}{$\begin{array}{l}\text { Tutors' } \\
\text { instruction }\end{array}$} & D1 & 0.456 & \multirow[t]{6}{*}{0.936} & \multirow[t]{6}{*}{0.717} \\
\hline & & D3.1 & 0.795 & & \\
\hline & & D3.2 & 0.896 & & \\
\hline & & D3.3 & 0.931 & & \\
\hline & & D3.4 & 0.954 & & \\
\hline & & D3.5 & 0.938 & & \\
\hline \multirow[t]{5}{*}{ Reinforcing factor } & \multirow[t]{5}{*}{ Environment } & D4.1 & 0.858 & \multirow[t]{5}{*}{0.969} & \multirow[t]{5}{*}{0.861} \\
\hline & & D4.2 & 0.918 & & \\
\hline & & D4.3 & 0.952 & & \\
\hline & & D4.4 & 0.96 & & \\
\hline & & D4.5 & 0.949 & & \\
\hline \multirow[t]{5}{*}{ Measurable variables } & \multirow[t]{5}{*}{$5 \mathrm{As}$} & Ask & 0.791 & \multirow[t]{5}{*}{0.958} & \multirow[t]{5}{*}{0.819} \\
\hline & & Advice & 0.912 & & \\
\hline & & Assess & 0.939 & & \\
\hline & & Assist & 0.952 & & \\
\hline & & Arrange & 0.922 & & \\
\hline
\end{tabular}

Note: CR, construct reliability; AVE, average variance extracted.

3.2.2 The discrimination validity of measurement model

Table 4 showed that the AVE values on the diagonal were higher than the square values of the correlation coefficients among other latent variables in the same row and column, indicating that the model was well discriminated.

Table 4 Discriminant validity 


\begin{tabular}{|llllll|}
\hline & Knowledge & Attitude & Resources & Instruction & Environment \\
\hline Knowledge & $\mathbf{0 . 3 7 2}$ & & & & \\
\hline Attitude & 0.029 & $\mathbf{0 . 5 7 9}$ & & & \\
\hline Self-efficacy & 0.029 & 0.274 & & & \\
\hline Resource & 0.003 & 0.228 & $\mathbf{0 . 6 6 6}$ & & \\
\hline Instruction & 0.007 & 0.308 & 0.286 & $\mathbf{0 . 7 1 7}$ & \\
\hline Environment & 0.015 & 0.287 & 0.268 & 0.621 & $\mathbf{0 . 8 6 1}$ \\
\hline
\end{tabular}

3.3 Model fit (confirmatory analysis of the fit)

Theoretical model was revised with fit index, correction index and theoretical experience after the path was analyzed by the least square method with AMOS 24.0. The absolute fit index $(=3.395, \mathrm{GFI}=0.937$; $\mathrm{AGFI}=0.922)$ and the reduced fit index $(\mathrm{PCFI}=0.678, \mathrm{PGFI}=0.756, \mathrm{PNFI}=0.682)$ of the model showed a good fit between the data and the model. See Table 5.

Table 5 Fit indices for the measurement model

\begin{tabular}{|llll|}
\hline Model Fit coefficient & Statistics & Reference & Good model fit $(\mathrm{Y} / \mathrm{N})$ \\
\hline$\square$ & 3.395 & $<5.00$ & $\mathrm{Y}$ \\
RMSEA & 0.042 & $<0.05$ & $\mathrm{Y}$ \\
\hline GFI & 0.937 & $>0.90$ & $\mathrm{Y}$ \\
$\mathrm{AGFI}$ & 0.922 & $>0.90$ & $\mathrm{Y}$ \\
PCFI & 0.678 & $>0.50$ & $\mathrm{Y}$ \\
PGFI & 0.756 & $>0.50$ & $\mathrm{Y}$ \\
\hline PNFI & 0.682 & $>0.50$ & $\mathrm{Y}$ \\
\hline
\end{tabular}

In sum, the measurement model showed good reliability, sufficient aggregation and discrimination validity. The fit of the data and the model was acceptable.

3.4 Analysis of the knot path of influencing nursing interns' 5 As in helping patients

Structural equation model estimated that path $\mathrm{H} 1(t=0.422, \mathrm{P}=0.673), \mathrm{H} 2(\mathrm{t}=1.930, \mathrm{P}=0.053), \mathrm{H} 5(\mathrm{t}=1.166, \mathrm{P}=0.244)$ did not work. That is, the direct influence of smoking cessation knowledge, attitude and resources of students' 5As did not present. Path H9 $(t=1.599, P=0.110)$ tobacco cessation education played no effect on the related knowledge, and $\mathrm{H} 10(\mathrm{t}=1.301, \mathrm{P}=0.193)$ smoking cessation environment had no effect on self-efficacy, while other paths were significant at the $P 0.05$ level. Tobacco cessation education directly influenced the nursing interns' 5 As $(\beta=0.542$, $P<0.001)$ in helping patients quit smoking, and had positive effect on self-efficacy $(\beta=0.380, P<0.001)$ and tobacco cessation attitude $(\beta=0.13, P<0.05)$, thus indirectly influencing 5 As behaviors. Smoking cessation environment (reinforcing factor) $(\beta=0.305, P<0.001)$ had direct effect on students' behavior, and had a positive effect on smoking cessation attitude $(\beta=0.201, P<0.001)$. Tobacco cessation resources $(\beta=0.305, P<0.001)$ had active effect on students' self-efficacy, indirectly influencing students' 5 As behaviors. The proficiency of 5As (self-efficacy) $(\beta=0.099, P<0.05)$ had direct effect on 5 As behaviors. The knowledge of smoking cessation $(\beta=0.08, P<0.05)$ had positive effect on self-efficacy, indirectly influencing 5 As behaviors. The attitudes towards tobacco cessation $(\beta=0.132, P<$ 0.05 ) had positive effect on knowledge and indirectly influenced the behaviors of 5 As. See Figure 2 for the path and coefficient of 5 As behavior effect of nursing students.

\section{Discussion}

This study, based on the theory of PREEDE, developed a structural equation model and analyzed the 5As behaviors that influenced the participation of nursing students in the tobacco cessation. It found that students scarcely performed smoking cessation behaviors ${ }^{[20]}$, and the enabling factor exerted the greatest effect on the implementation of tobacco cessation education; the next one was the reinforcing factor (the smoking cessation environment involving the smoking cessation behavior of the clinic tutor in the hospital); while the predisposing factor (knowledge, attitude and self-efficacy) had little effect on the implementation of 5 As.

The research path demonstrated that knowledge and attitude did not directly but through self-efficacy influenced the 5As behaviors, which was consistent with Bandura's interpretation of self-efficacy, that is, the judgment of knowledge and ability determined the motivation of behavior ${ }^{[23]}$. $\mathrm{H} 5$ tobacco cessation resources did not directly influence the 5Asbehavior, because people could change the 5As behaviors only after having mastered the knowledge and technology of the used resources and improved the self-efficacy of behavior implementation. Teachers' instruction had no effect on the knowledge of tobacco cessation, which might be attributed to that the knowledge was mainly about tobacco hazards, tobacco-related disease and regulations, while most of which was relatively common and students had mastered when they were learning the fundamental theories of health. Smoking cessation environment had no effect on self-efficacy. As mentioned above, it needed the corresponding resources and technologies to enhance the self-efficacy of 5 As behaviors. According to the study outcoming and the current situation of students' involvement in tobacco cessation, we suggested:

Page $7 / 11$ 
The study found that tutors' instruction, though not much, was the major factor that influenced students' 5 As behaviors to help smokers to quit ${ }^{[20]}$. Overseas schools had implemented theoretical education on tobacco cessation among medical students on campus and clinical tutors had administered intensive instruction on smoking cessation in practicum, which played significant roles in instructing students to help smokers to quit ${ }^{[15]}$. Previous studies ${ }^{[24]}$ reported that clinical nurses in China performed few smoking cessation behaviors on patients, which could be attributed to the lack of tobacco cessation education of knowledge and skills in their medical college study ${ }^{[25]}$ and the lack of relevant on-the-job training. In addition, the absence of the philosophy of disease prevention and health promotion and the responsibility to help patients to set up healthy lifestyles resulted in the lack of active study of the skills of disease prevention and health promotion. Therefore, along the call of Global Health Action, medical professionals should take a proactive leading role in tobacco cessation, stop smoking themselves firstly, help patients to quit smoking, and instruct students the skills of smoking cessation.

\subsection{Develop more effective smoking cessation resources}

Smoking cessation resources could provide assurance for students to implement 5 As behaviors. Literature reported that ${ }^{[26]}$ : smoking cessation resources were important factors that influenced medical professionals to offer smoking-quit assistance. Therefore, the establishment of professional tobacco cessation website, the construction of smoking cessation clinic, the research and invention of drugs to control smoking, the development and promotion of appropriate skills of smoking cessation, provided available resources for medical professionals and conditions for interns to implement smoking cessation behavior.

\subsection{Set up smoking cessation environment and culture}

The implementation of 5As behaviors by teachers had positive effect on students. China actively launched media publicity while consolidating regulations of smoking cessation, setting a good social environment ${ }^{[27]}$. Teaching hospitals should actively construct smoking-free hospitals, and develop a culture of actively helping smokers to quit, so that students would take behaviors consistent with the environment and felt that their behaviors were in line with social expectations and their behaviors would be reinforced, resulting in internal incentives to perform more behaviors to help others to quit smoking.

\subsection{Promote the course education of tobacco cessation among nursing students}

At present, more than 100 universities in China have established tobacco cessation courses ${ }^{[28]}$, but that for nursing students has not been reported. As the largest staff of medical professionals, nurses work the longer time with patients and most of them are female and non-smokers who are more active in smoking cessation ${ }^{[29]}$. It is of great significance to implement tobacco cessation education in nursing. Firstly, it can restrain the increase of the state of female smoking. The present female smoking rate in China is far lower than that of men. But in recent years, when the male smoking rate has reached saturation, tobacco producers and seller stake aim on women, depicting cigarettes as symbol of "independence", "freedom" and "equality" and they produce women cigarettes of "thin sticks" and "peppermint flavor", and advertise smoking as losing weight, subsequently women smoking rate gradually increases ${ }^{[30]}$.Actually, women smoking is not only harmful to their own health, but also to the newborn and the health quality of the next generation ${ }^{[31]}$. In addition, Chinese family education responsibility are mainly on women. Present nursing students are also future family educators. Their cognition and behavior of tobacco use directly influence the next generation's tobacco use behaviors. Therefore, the administration of tobacco cessation education among nursing students can achieve multiple effects such as reducing female smoking and the tobacco use of next generation.

This study is a confirmatory study based on the ecological theory of health education PREDEDE. A 5As behavior model that influences the nursing interns to help smokers to quit was constructed, and the relationship between various factors and the coefficient were tested, which provided further direction for the implementation of tobacco cessation education in nursing students to improve the 5 As skills. This study also has some limitations. Firstly, when designing the reinforcing factors, the main consideration was placed on the internal influence of teachers' smoking cessation behaviors on the awareness of participation of students. The external evaluation of students after the implementation of 5 As behavior was not included, and the internal motivation should also be taken seriously. Secondly, the dimension of knowledge mainly included the tobacco hazards and regulations related to tobacco cessation, little about the skills of 5 As. This may be attributed to the indirect effect of knowledge on 5 As behavior. There are various knowledge about tobacco cessation, and how to select to be included in the questionnaire needs to be further improved. Thirdly, the ratio of chi square and degree of freedom of the model was over 3 . It suggested that the fit degree of the model and the data needed further improvement although other fitting indexes indicated that the data fit well with the model. Fourthly, this survey was a self-report from students, which might be dishonestly over reported due to the bias of social expectations. Finally, although the relationship and the coefficient between the factors that influence the 5As behavior of nursing students had been analyzed, a causal judgment could not be achieved because the data in this study was collected from a cross-sectional survey.

\section{Conclusion}

The instruction of smoking cessation by instructors produced the greatest effect on students' behaviors, so the clinical teachers' responsibility and skills training of tobacco cessation should attract more attention. They should actively help smokers themselves and instruct students to use the 5 As to help smokers to quit in clinic. Hospitals keep going on the establishment of smoking-free hospitals, developing a good social culture of smoking cessation, and develop more effective tobacco cessation resources to urge medical professionals to help more smokers to quit.

\section{Abbreviations}

PROCEED: Policy, Regulatory, and Organizational Constructs in Educational and Environmental Development 


\section{Declarations}

\section{Ethics and consent}

It was approved by the Ethics Committee at the First Affiliated Hospital of Chongqing Medical University(2019-157).

Students were informed the voluntary participation and signed informed consent.

\section{Consent for publication}

Not applicable.

\section{Availability of data and materials}

The datasets used during the current study are available from the corresponding author on reasonable request.

All data analyzed during this study are included in this published article.

\section{Competing interest}

The authors declare that they have no competing interests.

\section{Funding}

This research was funded by the Humanities and Social Sciences Research Program (19SKGH024) from Chongqing Education Committee in 2019

\section{Authors' contributions}

All authors made substantial contributions to the conception and design of the study. Li Zhang is responsible for the acquisition of data; Li Zhang and Yetao Luo made analysis and interpretation of data; Yanhan Chen drafted the article and revised it, and approved the submitted version.

\section{Acknowledgement}

We thank the teachers and students who were involved in this research, and also thank all the preceptors and tutors who helped us to conduct the survey and all the students who completed the investigation. We give our thanks to the directors and managers for their close support from the nursing departments at the teaching hospitals.

\section{References}

[1]World Health Organization (2019) WHO report on the global tobacco epidemic, 2019:Offer help to quit tobacco use. Available at: https://www.who.int/tobacc

[2] Xianglong, X.; Doris, L.; Bing, L.;Pengfei, W.;\& Yong, Z. Smoking-related knowledge, attitude, social pressure, and environmental constraints among new undergraduates in chongqing, china. International Journal of Environmental Research and Public Health.2015, 12(1), 895-909.Doi:10.3390/ijerph120100895.

[3] Yang Y; Nan Y; Tu MW. Major finding of 2015 China adults tobacco survery. Chinese Journal of Health Management. 2016, 10(2):85-87.Doi:

0.3760/cma.j.issn.1674-0815.2016.02.002.

[4] World Health Organization. WHO Framework Convention on Tobacco Control. Geneva: World Health Organization; 2014. (accessed on 20 May 2020)

[5]Sarna L, Bialous SA. A review of images of nurses and smoking on the World Wide Web. Nurs Outlook 2012;60(Suppl 5):S36-46.

Doi:10.1016/j.outlook.2012.06.007.

[6] Geller AC, Brooks DR, Woodring B, Oppenheimer S, McCabe M, Rogers J, Timm A, Resnick EA, Winickoff JP. Smoking cessation counseling for parents during child hospitalization: a national survey of pediatric nurses. Public Health Nurs 2011;28:475-84.Doi:10.1111/j.1525-1446.2011.00954.x.

[7] Lenz B. K. Beliefs, Knowledge, and Self-Efficacy of Nursing Students Regarding Tobacco Cessation. American Journal of Preventive Medicine. 2008, 35(6):494-500.Doi:10.1016/j.amepre.2008.09.004.

[8] Lenz B K . Beliefs, Knowledge, and Self-Efficacy of Nursing Students Regarding Tobacco Cessation [J]. american journal of preventive medicine, 2008, 35(6supp-S). Doi:10.1016/j.amepre.2008.09.004.

[9] Jenkins, K. Ahijevych. Nursing students' beliefs about smoking, their own smoking behaviors, and use of professional tobacco treatment intervention Appl Nurs Res, 16 (2003), 164-172. Doi:10.1016/S0897-1897(03)00047-8.

[10] Duaso, Maria J, Bakhshi, Savita, Mujika, Agurtzane, et al. Nurses' smoking habits and their professional smoking cessation practices. A systematic review and meta-analysis[J]. International Journal of Nursing Studies, 2017,67:3-11.Doi:10.1016/j.jjnurstu.2016.10.011.

[11]Sreeramareddy CT, Ramakrishnareddy N, Rahman M, Mir IA. Prevalence of tobacco use and perceptions of student health professionals about cessation training: results from Global Health Professions Students Survey. BMJ Open. 2018;8(5):e017477. Published 2018 May 26. Doi:10.1136/bmjopen-2017-

Page 9/11 
017477.

[12] Sarna L , Bialous S A , Rice V H, et al. Promoting tobacco dependence treatment in nursing education[J]. Drug and Alcohol Review, 2009, 28(5):507-516. Doi:10.1111/j.1465-3362.2009.00107.x.

[13] Hyndman, et al., The Effectiveness of Tobacco Dependence Education in Health Professional Students' Practice: A Systematic Review and Meta-Analysis of Randomized Controlled Trials. International Journal of Environmental Research and Public Health, 2019. 16(21): 4158.Doi:10.3390/ijerph16214158.

[14] Park KY, Park HK, Hwang HS. Group randomized trial of teaching tobacco-cessation counseling to senior medical students: a peer role-play module versus a standardized patient module. BMC Med Educ. 2019;19(1):231. Published 2019 Jun 25. Doi:10.1186/s12909-019-1668-x.

[15] Ockene J K, Hayes R B , Churchill L C , et al. Teaching Medical Students to Help Patients Quit Smoking: Outcomes of a 10-School Randomized Controlled Trial[J]. Journal of General Internal Medicine, 2016, 31(2):172-181. Doi:10.1007/s11606-015-3508-y.

[16] Hayes R.B.; Geller A.C.; Crawford S.L.; et al. Medical school curriculum characteristics associated with intentions and frequency of tobacco dependence treatment among 3rd year U.S. medical students. Prev Med. 2015;72(3):56-63. Doi:10.1016/j.ypmed.2014.12.035.

[17] Green LW, Kreuter MW. Health program planning:an educational and ecological approach.4th ed. New York: McGraw-Hil, 2005:87-90.

[18] Tramm R, Mccarthy A, Yates P. Using the Precede-Proceed Model of health program planning in breast cancer nursing research. Journal of Advanced Nursing, 2012,68(8):1870-1880. Doi:10.1111/j.1365-2648.2011.05888.x.

[19] WANG Xiaoxiao, DUAN Hongwei, LIN Hang, WANG Aihong. Application of the PRECEDE-PROCEED model in health education: a literature review [J]. Chinese Nursing Management-2018,18(4): 570-574.Doi:10.3969/j.issn.1672-1756.2018.04.030.

[20] Zhang L, Chen Y, Lv Y, Yang X, Yin Q, Bai L, Luo Y, Sharma M, Zhao Y. The Perception and Intervention of Internship Nursing Students Helping Smokers to Quit: A Cross-Sectional Study in Chongqing, China. Int J Environ Res Public Health. 2019 Oct 13;16(20):3882. Doi:10.3390/ijerph16203882.

21.Hair, J. F., Black, W. C., Babin, B. J., Anderson, R. E., \& Tatham, R. L. (2010).Multivariate Data Analysis (7th ed.). New Jersey: Pearson Education Inc.

[22]Fornell, C., \& Larcker, D. F. Evaluating structural equation models with unobservable variables and measurement error. Journal of Marketing Research,1981,18(1), 39-50.

[23] Bandura A.Guide for constructing self-efficacy scales.In Adolescence and Education:Self-efficacy Beliefs of Adolescents, Pajares F, Urdan T (eds). Information Age Publishing: Greenwich, CT, 2006.29(1):307-337.

[24] Sarna, L.; Bialous, S. A.; Zou, X. N.; Wang, W.; Hong, J. , \& Chan, S. , et al. Helping smokers quit: behaviours and attitudes of Chinese registered nurses. Journal of Advanced Nursing. 2016,72(1):107-117. Doi:10.1111/jan.12811.

[25] Chan S.S., Sarna L., Wong D.C. \& Lam T.H. (2007) Nurses'tobacco-related knowledge, attitudes and practice in four major cities in China. Journal of Nursing Scholarship 39, 46-53. Doi:10.1111/j.1547-5069.2007.00142.x.

[26]Chang Y. Y.; Yu S. M.; Lai Y. J.; et al. Improving smoking cessation outcomes in secondary care: Predictors of hospital staff willingness to provide smoking cessation referral. Preventive Medicine Reports. 2016, 3:229-233.Doi:10.1016/j.pmedr.2016.02.002.

[27] Wu S S.; Zhang X.; Wang M L .; et al. Positive effect of New Media on Public Tobacco Control [J]. China Journal of Health Psychology,2017,25(1)『88-92. Doi:10.13342/j.cnki.cjhp.2017.01.022.

[28]Lin H X.; LI Y .; Xiao L. Current situation and suggestion on developing tobacco control curriculum in universities of China[J]. Chinese Journal of Health Education. 2016, 32(2):174-177.doin10.16168/j.cnki.issn.1002-9982.2016.02.022.

[29]Frank E, Elon L, Spencer E. Personal and clinical tobacco-related practices and attitudes of U.S. medical students. Preventive medicine. 2009 Aug-Sep;49(23):233-9.Doi:10.1016/j.ypmed.2009.06.020.

[30] Tobacco Control Office, Chinese Center for Disease Control and Prevention. 2010 China Smoking Control Report $\otimes E B / O L \otimes . h t t p: / / w w w . c a t c p r c . o r g . c n /$ index.aspx?menuid=22\&type=articleinfo\&lanmuid=139\&infoid=2214\&language $=c n$

[31] Zhang I.; Zhu X. B.; Li J.; et al. Prevalence and influencing factors of smoking among nursing students. Chinese Journal of Public Health. 2015, 31(6): 730733. Doi:10.11847/zgggws2015-31-06-11.

\section{Figures}




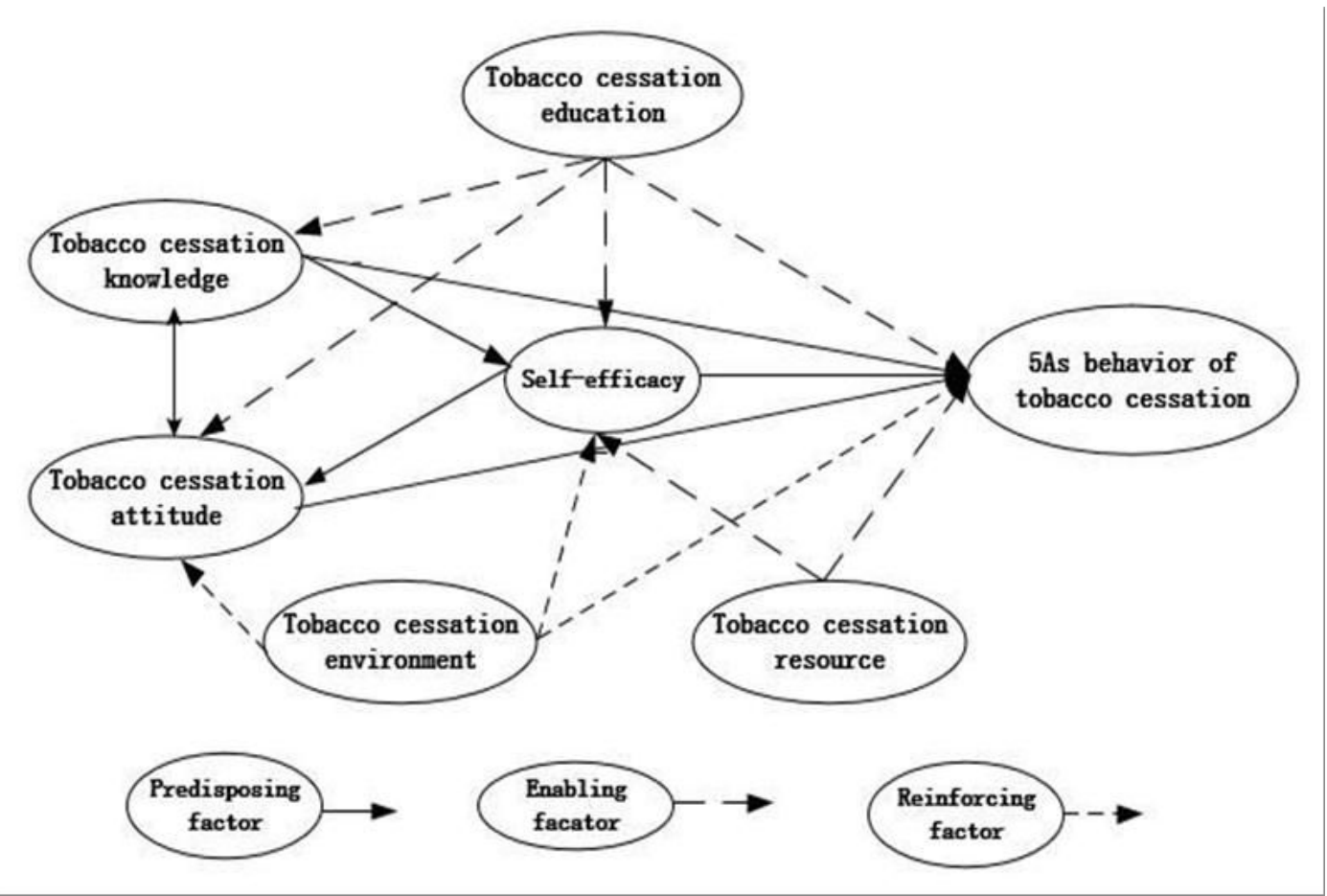

Figure 1

Influencing factors and correlations of 5As in tobacco control among nursing students based on PRECEDE theory

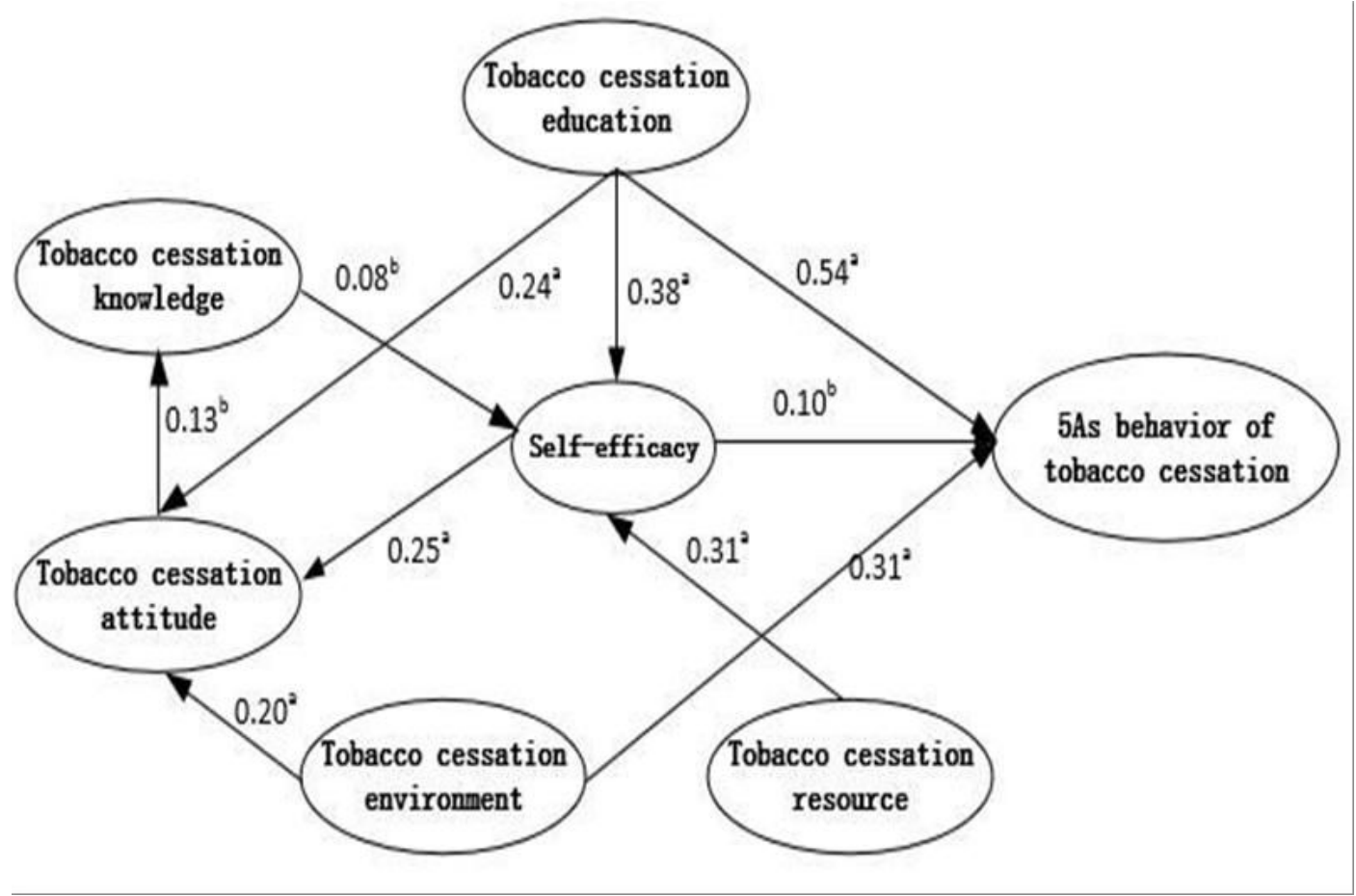

Figure 2

The path and standardized regression coefficient of the effect of smoking cessation behavior model of nursing students. Note $\mathbb{a P}<0.001 \rrbracket \mathrm{bP}<0.05 \rrbracket$ 